\title{
Existing Software Stakeholder Practices an Overview
}

\author{
Smiju Sudevan \\ Cochin University of Science and \\ Technology, Department of \\ Computer Applications, \\ Cochin, India
}

\author{
M. Bhasi \\ Cochin University of Science and \\ Technology, School of \\ Management Studies \\ Cochin, India
}

\author{
K. V. Pramod \\ Cochin University of Science and \\ Technology, Department of \\ Computer Applications, \\ Cochin, India
}

\begin{abstract}
Software technology is an everchanging and dynamic science. As in other spheres, here too, despite the vast extent of interactive and participatory software practice and theory, there is still little shared understanding amongst those involved. The success of a software project is directly affected by the lack of understanding and estimating stakeholder's needs and expectations along with lack of effective communication amongst the software stakeholders. The following paper aims to understand the existing software stakeholder management techniques in IT industry. This will further help in dealing with unforeseen circumstances and potential risks.
\end{abstract}

\section{Keyword}

Stakeholder, Software management, Stakeholder management, Stakeholder Identification, Stakeholder analysis

\section{INTRODUCTION}

As software development projects adapt to changing circumstances, management of those projects must also adapt. The project management environment is fluid: responsibilities, and therefore knowledge or skill levels required, migrate up and down the organizational chart depending on the project, the people available and even the phase that the project is in[1]. One of the key skills in project management, therefore, is to be flexible and to adapt to any situation. Such changes could involve adopting different development lifecycles, moving to component based software development or distributing the development. While the project management objectives may remain the same, the mechanism used to achieve those objectives will not necessarily remain unchanged and adaption would be assisted through understanding which mechanisms are used in different circumstances. Such knowledge of the mechanisms could guide the ways in which project managers adapt to different project environments as well as guide efforts to develop project work flow and project management tools. Software and web services companies have faced new challenges. The adoption of project management is seen as a method for solving such organizational problems [7]. Software project management has proved to be one of the most difficult tasks in software development business. Project management is an important part of software development, both for organizations that rely on third-party software development and for those whose software is developed primarily in-house. Software Project management is now well developed and well accepted as a domain for the exercise of professional expertise and as an area of academic research and discourse. Some studies had focused on problems in software development projects. The software literature provides many published papers and surveys that report alarming figures for software project failures at various levels or discuss inconvenient project situations. The Standish survey shows that less than $50 \%$ of software projects can be classified as successful. That is only less than $50 \%$ of the projects are completed on time within the budget and covering the scope. This knowledge was found to be very alarming [14]. It is possible that poor project management knowledge and skills in software companies lead to the project failures [12]. Another main determining factor that played a role in the success of projects was "stakeholders". There has been little research on stakeholder management compared with the other knowledge areas of project management [5].

\section{THE ROLE OF STAKEHOLDER}

The entire process of software project management is strongly stakeholder-driven. It is their stakes - that determine the course of the project. A team will have to deliver a project under time pressures to appreciate the constructive power of motivated people or the destructive power of demotivated team members. In a project, it is the people that are the main cause of problems. Time schedules, financial projections, and software goals may be abstractions, but it is the flesh-and-blood people whose work determines the project's status. Stakeholders are individuals and organizations "who are actively involved in the project, or whose interests may be positively or negatively affected as a result of project execution or successful project completion" (Project Management Institute, 2011).

\subsection{Changing perceptions of Stakeholders}

According to Hitt, Freeman and Harrison (2001) the use of the term stakeholder emerged in the 1960s from pioneering work at Stanford Research Institute, which argued that managers "needed to understand the concerns of shareholders, employees, lenders and suppliers, in order to develop objectives that stakeholders could support". The term has become increasingly prevalent since Freeman's (1984) seminal text "Strategic Management: A Stakeholder Approach". The stakeholder approach was found to be a strategic management tool[2] - instrumental as opposed to normative - the emergence and establishment of a social performance agenda for business has highlighted the value of stakeholder theory as a "normative approach that some argue is more ethically and morally acceptable than a shareholder value approach" [3] . Since the mid 1990s, this question of the legitimacy of stakeholder claims on organizations has emerged as central to the debate relating to corporate social responsiveness and corporate responsibility .The global meltdown of financial markets and widespread corporate collapses of 2008 re-focused public debate sharply on questions of the relationship between business and society and the design of the corporation of the future - "shifting the purpose of the firm to encompass not just shareholder needs but also societal, stakeholder and ecological needs and interests" [6]. The business benefits of effective stakeholder engagement are now wellknown and well-documented. A number of studies have found a clear correlation between stakeholder relationship quality and financial performance [4]; sustainable wealth/long-term value [7] and corporate reputation [4]. Svendsen (1998) argues the case for competitive edge as an outcome of effective stakeholder engagement: "as paradoxical as it sounds, one way to succeed in a highly competitive globalised economy is to co-operate". The central claims for an integrated approach to stakeholder 
engagement arguably center primarily on benefits to the organization - essentially on the view that "incorporating stakeholder views in decision-making processes enhances organizational performance and commitment" [12]. The value of on-going stakeholder engagement via processes of dialogic and two-way symmetrical communication to invite stakeholder input into organizational decision-making has been pointed out[13]. There is indeed substantial evidence in the stakeholder and communication management literature to suggest that enlightened organizational strategy-making is best informed by a process of continuous dialogue with stakeholders and that "the social performance of any business should be judged not by what it does, but by the extent to which it facilitates interested parties in negotiating what it does[5].In seeking operational definitions of sustainable corporate practices and corporate social responsibility, the need to embrace corporate systems and practices which reflect the interests of a wide range of stakeholders or constituents has been stressed by various authors[4][8][10]. Arguments have been put forth that it is these parties engaged in a productive dialogue that can provide requisite knowledge required to resolve the longer-term challenges of sustainable development triple bottom line performance [7]. Earlier research has shown that the sustainable corporation must demonstrate the ability to learn from

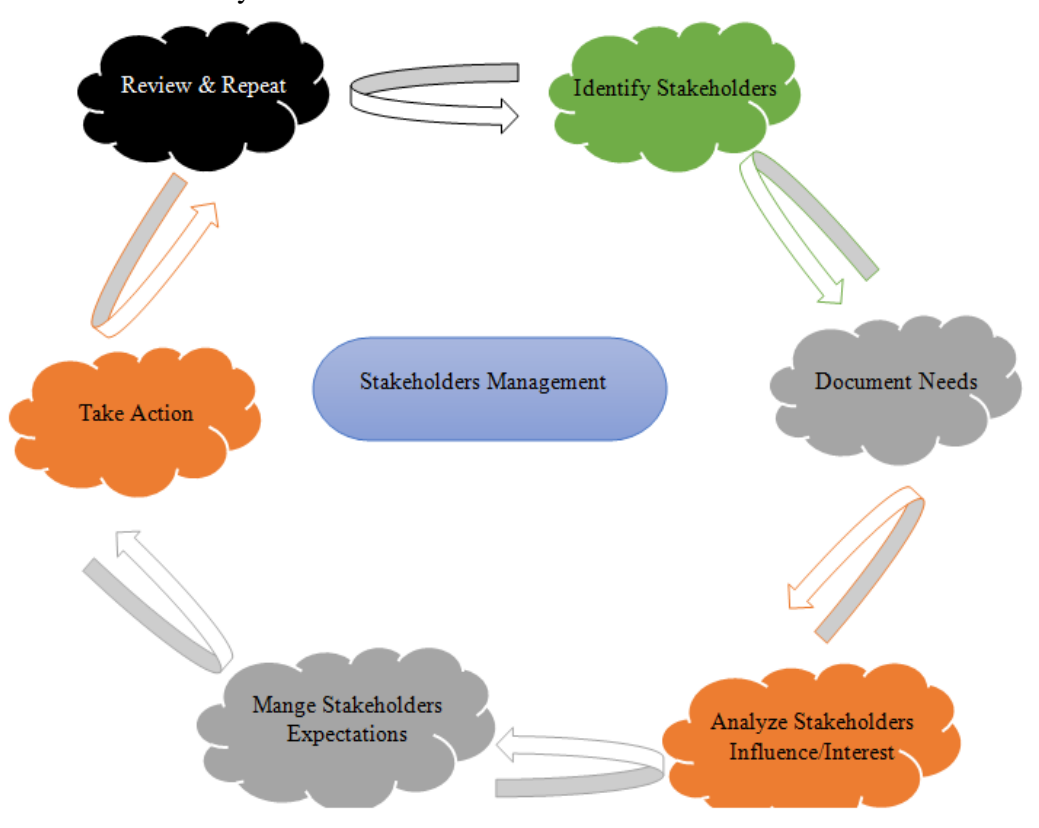

Figure 1: Stakeholder management cycle depicting levels

The different processes can vary according to the different software development processes and organizational goals. Fig 1 shows a common cycle of stakeholder management cycle involving key processes. Stakeholder Management is considered one of the first organizational strategies in most of the software projects. There are many different models but three key areas are important. This paper intends to dwell on them.

\section{STAKEHOLDER IDENTIFICATION}

Stakeholder identification plays a key role in the stakeholder management effort and in analysis. The stakeholder identification process is the very first steps taken in initiating a new project [8]. It is a precursor to stakeholder analysis report. Only if stakeholder identification is done initially, can the requirements of the project can be elicited. It is the stakeholder that can give access to system manuals, users, maintenance logs, and the myriad of other assets that can be leveraged during the requirement elicitation phase [25]. stakeholders and previous mistakes, through a continuous process of consultation, measurement, auditing and reporting [8].

\section{STAKEHOLDER MANAGEMENT AND PROJECT SUCCESS}

The success of a project depends on how stakeholders are handled. The successful management of stakeholders can have a substantial and immediate impact- satisfied stakeholders can greatly improve the progress and relevance of a project and ultimately contribute significantly to its success. A typical software quality and expectation is the lack of defects. A software product that was thoroughly tested and bug free may not meet current or future stakeholder expectation. Looking at the broader definition of software quality, the project manager in the project described can identify all of the stakeholders- Project team, software supplier, user department and the IS department manager. Each of these stakeholders has a different reason for having an interest in the software system, which influences their behavior. Management of these "stakeholder interests" is referred to as Stakeholder Management. While this is important in every project, it is especially important in software development where deliverables are not tangible [9].

The first step concerned is with the phase "Who are the stakeholders", Stakeholders are all those who need to be considered in achieving project goals and whose participation and support are crucial to its success. Stakeholders can be 1) individuals within the project 2) individuals and groups within the organization and 3 ) individuals or groups outside the organization. Thus, there are many software stakeholders to be identified for a project.

The following are the different ways to identify stakeholders who play a role in the software project. In doing this, the main objective is to try to break the large group of stakeholders into smaller groups since large groupings can impact the value of information gained from the process.

1) Category Approach: It is the most commonly used method where categories of stakeholders are created by the project team based on past experience and theses are then used to identify 
stakeholders. The risk of this approach is that it may be too broad resulting in overlooking of some stakeholders.

2) Role Approach; The project team works from a generic list of stakeholder roles. Because the roles are very generic, this approach makes it easy to overlook stakeholders who don't have a direct interactive role in the system or project.

3) Interview Approach: The interview method is most useful for identifying new stakeholder roles and new individuals to potentially fill those roles. Unfortunately it is time consuming and is found to be unfeasible in majority of software projects.

4) Search Approach: Here stakeholder specific roles are identified that are appropriate for the project. While this approach will usually result in a more complete stakeholder list a key issue is knowing when to stop.

5) Following Approach: The approach follows some specific artifact through the software project management lifecycle to identify the stakeholders who provide or use that artifact, or who have responsibility for it in some way. This approach helps in identifying new stakeholders to the project as well as missing many stakeholders that are not part of the specific artifact that is being followed.

6) Goals approach is another way to identify stakeholders which is used extensively in software industry.

The results of the Stakeholder Identification effort should include a complete list of stakeholder roles as possible given the knowledge at that time, the above information is classified and put in the stakeholder registry. Though initially most of the software companies did not deem it necessary to have a registry [27], changing times have prompted most of them to give due importance's for stakeholder identification and putting up a registry in the initial phases of the project itself.

An approach that is used in software industries to identify the different stakeholder roles is by using the onion diagram as shown in fig 2 .

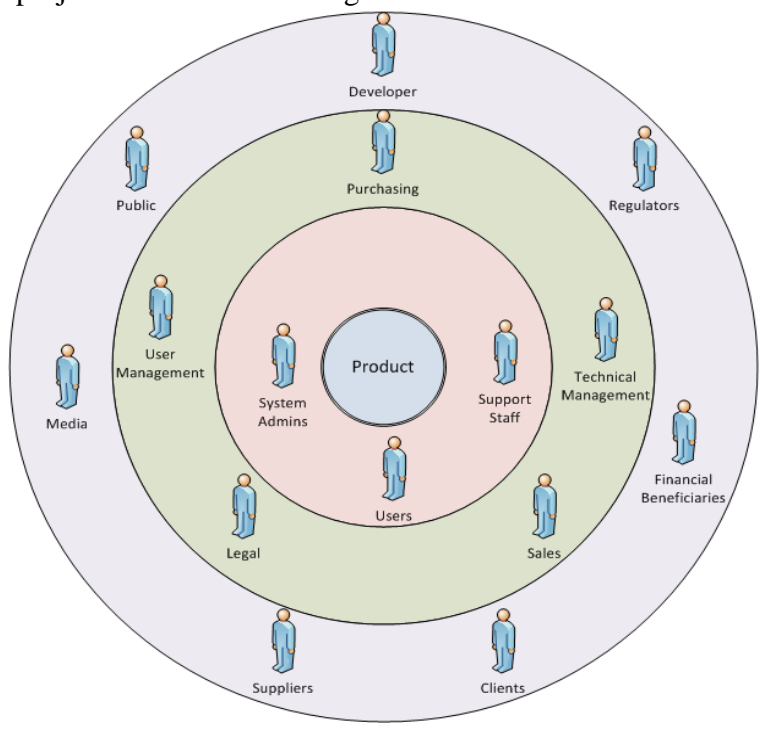

Figure 2:Onion diagram representing stakeholder roles

\section{STAKEHOLDER ANALYSIS IN SOFTWARE}

A stakeholder analysis is a process for providing insights into, and understanding of, the interactions between a project and its stakeholders [10]. It is a powerful tool to help project members identify and prioritise stakeholders who can have an impact on project success. It can prompt thinking about the type of influence individuals have and in what way they might be an asset (or hindrance) to achieving successful outcomes. It is an essential starting place for understanding critical stakeholders and is the first step for developing engagement strategies for building and maintaining the software networks that are necessary for the delivery of successful project outcomes. Undertaking a stakeholder analysis can be an important first step in managing the stakeholder that determine the stakes and expectations of the stakeholders, and adopt the project organization and feedback mechanisms according to the desired outcomes [9]. A major benefit for a team undertaking a stakeholder analysis during the planning and development stages of a project is the opportunity to have an insightful conversation about their project and stakeholders. This may result in the whole team developing a clearer understanding of the range of project stakeholders, thus helping to develop a more focused approach towards the project. The first step of stakeholder analysis is identification of the stakeholders which is done in the initiation phase. This has already been dwelt upon previously.

\subsection{Identify Behavioral Influences}

Projects are developed in an organizational environment within a company, consisting of functional departments with organization goals and objectives [21]. These goals and objectives evolve as the organization reacts to market and other environmental impacts. Project managers need to identify and interact with key organizations and individuals within the project systems environment. This management process is necessary to determine how the stakeholders are likely to react to project decisions, what influence their reaction will carry, and how they might interact with each other and the project manager to affect the chances for project success [11]. The impact of project's strategy and decisions on all the stakeholders must be considered in any rational approach to the management of a project. Stakeholders can be categorized by the amount of influence they can have over the project success. This means not only identifying the level of influence the stakeholder has within the business overall, but also the level of influence they may have on the projects budget, access to resources, implementation, 
persuasive influence over key decision-makers, or control of critical knowledge[7]. Indeed, the project team may want to map each stakeholders influence level across multiple aspects of the project space (such as budget, resources, knowledge) in order to more fully understand their potential impact as well as when to best engage with each stakeholder. An important point to remember is that Influence is not the same thing as Power[17]. A stakeholder can have a small amount of Power in the capability of making and enforcing decisions, but they may be a trusted advisor to someone who does have that power, making their influence higher than their power. It is necessary to examine the power of stakeholder influence especially in two areas;

1. The ability of the stakeholder to influence the outcomes of the project. For example, the funders have a large impact on the outcome of the project as if they do not agree with the outcomes of the project they are unlikely to fund the project.

2. The stakeholder's ability to influence how the outcomes will be met. For example, the technical and the administration staff on a project are unlikely to have an impact on the outcomes of the project but are likely to have a significant impact on how the outcomes are achieved.

\subsection{Develop Communication Strategy}

Once the stakeholders are identified and their interests are identified and their interests understood, the most important activity as a project manager is to define the project goals, scope and end results. While organizational goals may have initiated the project, these goals may not have considered all of the stakeholders [8]. The project manager must revisit the project deliverables with all of the stakeholders, and process the information received from the stakeholders. This understanding must then be articulated back to the stakeholders to obtain definition and agreement. In all cases, this definition and agreement must be documented. Not only are these goals, scope and end results established at the start of a project, but they must also be communicated throughout the project lifecycle. Again, a project is developed in a dynamic organizational environment. The project manager must manage stakeholder expectations by listening to current business needs, addressing any yet unstated stakeholder requirements, and adjusting project deliverables to address those needs [1]. What was perceived as a need a year ago when the original goals and scope were defined may not be what is needed now. The project manager must also be sure that the project owner, the IS Manager in this case, is clear on project goals and objectives. The IS Manager can assist in managing business requirements, acquiring additional resources to meet changing needs, and breaking down organizational barriers to success[18]. With clear goals and objectives, the project manager also can direct the project team towards the agreed upon requirements [21]. Given the most talented people in the company on the project, the project team still cannot reach the goal without a clear target. The goals and objectives must also be communicated to the end users of the software. In return, the project manager must listen to the needs and concerns of the users, and assure them that their concerns are understood. User 'buy-in' is key to managing their expectations. Methods to obtaining user 'buy-in' can include prototyping interfaces and conducting training early in the design phase to solicit user feedback. Obviously the more the user interface differs from the current system, the more resistance will be expressed by the user. It is important to keep this aspect in mind when developing the end user communication strategy as it will mostly definitely impact their behavior. If a software supplier is used, the project manager must also communicate goals and objectives to the supplier and make these parts of the contract. In need of special attention, but often overlooked is the contractual training to be provided [10]. Often, training is conducted once after the design is mostly complete, which may be too late to accommodate specific needs. Typical training provided by the software supplier is a 'show-and-tell' class, and may not address the users' deepest concerns, for instance 'How will I use it on my job?' While a good introductory class, this type of 'show-andtell' class may present more questions for the users than answers, creating a stage for animosity. The project manager should use this opportunity to address the concerns of the project team. The stakeholder communication strategy should address the stakeholder commitment level. For this, first of all, the required commitment level (from the stakeholder's identification sheet) is compared with the current commitment level (based on the Stakeholder Analysis).After this is done, a communication strategy is prepared to close the gap between current and required commitment and also to maintain the required commitment level. This may include methods of leveraging strong support from powerful stakeholders or by means of mitigating the opposing stakeholders.

The communication style needs to control both the project content as well as the audience involvement. The "tell" style is used when there is a need to control the content of the communication, In these cases, the project manager has sufficient information in explaining and instructing. The Project Status report is an example of "tell" communication. The "sell" style is used when the project manager has to advocate or persuade and needs the audience involvement. Project proposals and change request recommendations are examples of "sell" communication. The "consult" style is used when the project manager needs input, but wants to control the interaction. This style is helpful when learning and managing stakeholder expectations. Examples of the "consult" style include requirement workshops or scope definition meetings. The "join"style is a coordinating style where the stakeholder's commitment is needed or sought. Issue resolution, conflict management and risk identification are examples of the "join' style. The above is portrayed in fig 3 as shown below 


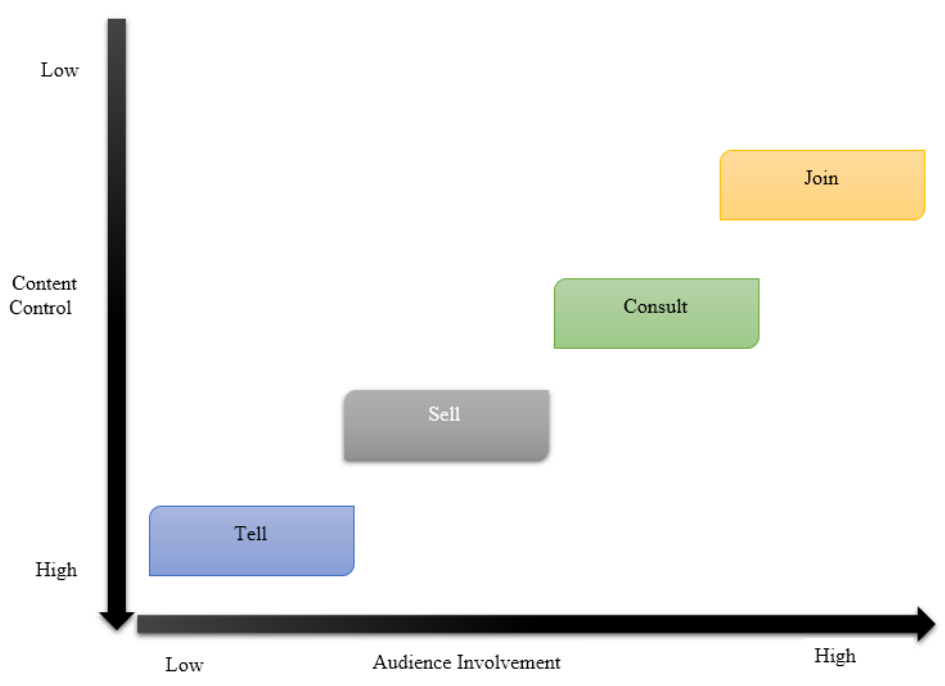

Figure 3: An effective communication strategy

\subsection{Stakeholder Expectations and Interests}

Stakeholder engagement and/or participatory practice is increasingly becoming a part of mainstream software business practice and central to company decision-making and delivery .They are the various expectations that they have since the starting of a project[17]. The project requirements thus have to stay in line with what people are expecting. If stakeholders find out the requirements don't fit their expectations, there will be a major problem. Knowledge about the stakeholders and their expectations and interests helps to shape the project organization (structure, authority, and responsibility)[14]. Taking stock of such expectations during the initial stage is a very good risk analysis strategy to see where the potential problems will be.

Stakeholder engagement should be at the heart of any "sustainable development" agenda. Without engaging stakeholders, there can be no common enduring agreement, ownership or support for a particular project. A venture is more likely to succeed, especially in the long-term, if it takes into consideration the environment in which it operates and endeavors to meet the needs of the stakeholders affected by it[3]. Stakeholder engagement could be viewed as a form of risk management. Many projects, but not necessarily all, will need to engage with a wide range of stakeholder groups, each with their own concerns, needs, conflicts of interest and levels of influence [21]. In order for the pieces of the project plan to be effective, planners and project managers need to understand who are the stakeholder groups, what their issues are, and what motivates them. As it is seen that no two software development projects are ever identical - varying in requirements, constraints, funding partners and timescales - one cannot expect to replicate the participation process of one project (no matter how successful) to produce the same results in another. Rather, it is necessary to treat each process separately, learning from the lessons of similar projects but recognizing where there is room for improvement[20]. If we look at the average interest levels of stakeholders and engagement levels of stakeholders, it runs generally fairly interested early on in the project and then there's a gradual decline in interest levels and stakeholder engagement levels. This change depending on the project and the size. It

starts to increase again towards the end as the project nears its handover point or the transfer of risk where that project becomes business as usual and into the stakeholder's ownership. This may lead to changes, or if the situation demands a new functionality.
There are many research works being done on stakeholder engagement theories in the software sector[15].

\section{CONCLUSION}

Stakeholder management thus enables in managing stakeholder's expectations and ensuring their active involvement in the project from the initiation stage itself. There seems to be an assumption that Stakeholder Identification is an easy and relatively straightforward process. In reality, achieving a complete stakeholder list seems to be anything but simple. Remember that the purpose of the Stakeholder Identification process is to identify all stakeholders, not which specific stakeholder will best fit a specific stakeholder role. That is determined in Stakeholder Analysis. This paper thus wants to review that stakeholder identification is the most important followed by communication. Only by communicating, can we engage the stakeholders and make the project a success. There are various models for communication suggested by researchers in various fields, often other than software engineering, but the general principles of managing stakeholders and communicating effectively still apply, and these frameworks can be tailored based on the requirements for any project.

\section{REFERENCES}

[1] Hitt, M., Freeman, R. \& Harrison, J. (2001). The Blackwell Handbook of Strategic Management. Hoboken, NJ: WileyBlackwell Publishers Ltd.

[2] Freeman, R.E. (1984). Strategic Management: A Stakeholder Approach. Boston: Pitman

[3] Cooper, SC (2004). Corporate Social Performance: A Stakeholder Approach. England: Ashgate Publishing Limited.

[4] Dowling, GR. (1994). Corporate Reputations- Strategies for Developing the Corporate Brand. Melbourne: Longman Professional.

[5] King, A. (1998). The social performance uncertainty principle. Corporate Reputation Review, v 1, no 3, pp 4346. Henry Stewart Publications.

[6] Waddock, S. \& McIntosh, M. (2009). Beyond corporate responsibility: implications for management development. Business and Society Review, Fall, v 114, no 3, 295.

[7] Post, J., Preston, L., \& Saschs, S. (2002). Redefining the Corporation. Stakeholder Management and Organizational 
Wealth. Stanford Business Books. California: Stanford University Press.

[8] Ronald K. Mitchell, Bradley R. Agile, Donna J. Wood, (1997).Toward a Theory of Stakeholder Identification and Salience: Defining the Principle of Who and What Really Counts, The Academy of Management Review,pp. 853-886

[9] Ken Power, (2010). Stakeholder Identification in Agile Software Product Development Organizations - A model for understanding who and what really counts, IEEE Publication, pp 87-94, AGILE Conference

[10] Bendik Bygstad,(2004) Controlling Iterative Software Development Projects: The Challenge of Stakeholder and Technical Integration - System Sciences,Proceedings of the 37th Annual Hawaii International Conference,2004

[11] Svendsen, A. (1998) The Stakeholder Strategy. Profiting from Collaborative Business Relationships. San Francisco: Berrett-Koehlert Publishers Inc

[12] Simmons, J. (2003). Balancing performance, accountability and equity in stakeholder relationships: towards more socially responsible HR practice. Corporate Social Responsibility and Environmental Management 10, 129140

[13] Grunig, J. (1992). Excellence in Public Relations and Communication Management. New Jersey: Lawrence Erlbaum Associates

[14] R.L. Glass, (2002) "Failure Is Looking More Like Success These Days," IEEE Software, vol. 19, no. 1, 2002, pp. 103104.

[15 ]Naemura, Kenji (1995) User Involvement in the life cycles of Information Technology (IT) and telecommunication standards. The Politics and Economics of Standards in natural and technical environments. Edward Elgar, Adershot, UK/Brookfield, US, pp.93-102.

[16] Lim.S.L,Bentley.P.J,2011.Evolving relationships between social networks and stakeholder involvement in software projects. In: Proceedings of the 13th Annual conference on Genetic and Evolutionary computation, Doublin, Ireland, pp.1899-1906.
[17] Lewis, CW.1991, Understanding who and what matters: Stakeholder analysis, Jossey-Bass, CA, USA

[18] Lim.S.L,Quercia,Finkelstein.A,2010 StakeNet:using social networks to analyze the stakeholders of large-scale software projects, In:proceedings of ACM/IEEE 32nd International Conference on Software Engineering, Cape Town, South Africa,vol.1.pp,295-304

[19] R.K.Mitchell, B.R.Agile and D.J.Wood, "Toward a Theory of Stakeholder Identification and Salience: Defining the principle of who and what really counts," Academy of management review, vol.22, no. 4, pp.853-886, October 1997.

[20] K.Power," Software Development: A Stakeholder Approach (PhD Thesis),"J.E.Cairnes School of Business \& Economics, National University of Ireland, Galway, In Progress.

[21] K.Power,"DynamicStakeholder relationships in Software development Organizations," In progress, 2010.

[22] Coughlan J, Lycett M, Macredie RD (2003) Communication issues in requirements elicitation: a content analysis of stakeholder experiences,Inf Softw Technol 45(8):525-537

[23] Coughlin J, Lycett M, Macredie RD (2002) Effective Communication in requirements elicitation:comparison methodologies.requirEng J $7(2): 47-60, \quad$ doi: $10.1007 / \mathrm{s} 00766020004$

[24] Khalifa G,Irani Z,Baldwin LP,Jones S(2000) Evaluating Information technology with you in mind .Electron J Inf Syst Eval 4(1):Paper 5

[25] Pacheco C, Tovar E(2007) Stakeholder Identification as an issue in the improvement of Software Requirements Quality.krogstie J,Opdahl AL,Sindre G(eds) CAiSE 2007,LNCS 4495,pp 370-380

[26] Pan GSC (2005) Information Systems project abandonment: a stakeholder analysis.Int J Inf Manag 25(2):173-184, doi:10.1016/j.ijinfomgt.2004.12.003

[27] Sharp H.Finkelstein A, Galal G(1999) Stakeholder Identification in the requirements engineering process .DEXA workshop 1999:3876-391 